\title{
MAPPING BURN SCARS, FIRE SEVERITY AND SOIL EROSION SUSCEPTIBILITY IN SOUTHERN FRANCE USING MULTISENSORAL SATELLITE DATA
}

\author{
S. Martinis ${ }^{1}$, M. Caspard ${ }^{2}$, S. Plank ${ }^{1}$, S. Clandillon ${ }^{2}$, S. Haouet ${ }^{2}$ \\ ${ }^{1}$ German Aerospace Center (DLR), German Remote Sensing Data Center, \\ Oberpfaffenhofen, 82234 Wessling, Germany \\ ${ }^{2}$ Service Régional de Traitement d'Image et de la Télédétection (SERTIT), Illkirch Graffenstaden, France
}

\begin{abstract}
This article focuses on the mapping of fire burn scars, fire severity and soil erosion susceptibility using multi-sensoral satellite data. An automatic procedure for the mapping of fire affected areas and for the estimation of fire severity using Sentinel-2 data is presented. The Sentinel-2 based classification results are compared to a burn scar derived by a semi-automatic object-based approach using Sentinel-1 amplitude and coherence time-series data systematically processed by the Sentinel-1 InSAR Browse service implemented on the Geohazard Exploitation Platform (GEP) of ESA. Further, a transferable approach to compute a soil erosion susceptibility index based on Pléiades data is presented. The SAR- and optical-data based methods are applied in a test area near Marseille/Vitrolles, France, which was affected by severe forest fires in August 2016.
\end{abstract}

Index Terms - Burn scar mapping, fire severity, Sentinel-1/2, time-series, Geohazard Exploitation Platform

\section{INTRODUCTION}

Both optical and radar satellite remote sensing have proven to provide essential crisis information in case of natural disasters and covering humanitarian relief activities and civil security issues in a growing number of cases through mechanisms such as the International Charter 'Space and Major Disasters' or the Copernicus Emergency Management Service (EMS) of the European Commission. These programs and initiatives make use of satellite-based rapid mapping services aimed at delivering reliable and accurate crisis information during or after natural disasters.

Although these services are increasingly operational, they need to be continuously updated and improved through research and development activities. This work is conducted in the project ASAPTERRA (Advancing SAR and Optical Methods for Rapid Mapping) funded by ESA. It has the objective to improve, automate and, hence, speed-up geoinformation extraction procedures in the context of natural hazards response with a focus on fires, floods and landslides.
This is performed through the development, implementation, testing and validation of novel image processing methods using optical and Synthetic Aperture Radar (SAR) data. A major focus of the project is on Sentinel-1/2 (S-1/S-2) data. Due to the systematic, conflict-free, observation scenario of the S-1 and S-2 mission most parts of the Earth's surface will be covered within a repeat cycle of up to six and five days, respectively. This is leading to new applications in time-series analysis and SAR Interferometry (InSAR), which make these missions particularly suitable for monitoring geohazards and rapid mapping activities.

This study focuses on rapid mapping related to forest fires. Forest fires do not only pose an urgent threat to land and life but also contribute to erosion, land degradation, and cause long-term damage to vegetation and soil moisture. Furthermore, the large amounts of smoke emitted from fires impact air quality and affect global warming due to rising trace gas emissions [3].

The objective of this study is threefold: 1) to develop an automatic procedure for burnt area mapping and for fire severity estimation (called BURNOUT) based on optical S-2 data and 2) a transferable approach to compute a soil erosion susceptibility index based on Pléiades data. Further, 3) there is a focus on testing the suitability of the synergistic use of amplitude and coherence S-1 time-series data of the Sentinel-1 InSAR Browse service implemented on the Geohazard Exploitation Platform (GEP) of ESA for burn scar detection. The SAR- and optical-data based methods are tested and compared in a study area near Marseille/Vitrolles, France, which was affected by severe forest fires in August 2016.

\section{STUDY SITE AND DATA SET}

The study area is located in the Rognac commune, located to the north of Marseilles, France. The fires lasted from 10/08/2016 to $12 / 08 / 2016$ and ravaged nearly 2600 ha of scrubland and pine trees damaging several buildings, especially in Vitrolles and Les Pennes-Mirabeau. For the extraction of the burnt area based on optical data both S-2 
and Pléiades crisis have been acquired on 13/08/2016 and could be compared to adequate pre-event data (table 1).

Via the Geohazard Exploitation Platform (GEP) of ESA, an S-1 InSAR Browse service, developed by DLR and Terradue, is provided, which gives direct access to a powerful processing capacity to exploit large Earthobservation datasets. Based on pairs of S-1 data from consecutive passes this service systematically provides an interferometric product at up to $50 \mathrm{~m}$ resolution. For the study area a time series of five VV-polarized S-1A data (01/07/2016-18/08/2016) with a temporal baseline of 12 days have been used to compute four interferometric pairs.

Tab. 1: Data set.

\begin{tabular}{|c|c|c|}
\hline Sensor & Resolution $(\mathbf{m})$ & Acquisition date \\
\hline Pléiades-HR1B & 0.5 & $13 / 08 / 2016$ \\
\hline Pléiades-HR1B & 0.5 & $21 / 04 / 2015$ \\
\hline Sentinel-2A & 10 & $13 / 08 / 2016$ \\
\hline Sentinel-2A & 10 & $24 / 07 / 2016$ \\
\hline Sentinel-1A & 50 & $18 / 08 / 2016$ \\
\hline Sentinel-1A & 50 & $06 / 08 / 2016$ \\
\hline Sentinel-1A & 50 & $25 / 07 / 2016$ \\
\hline Sentinel-1A & 50 & $13 / 07 / 2016$ \\
\hline Sentinel-1A & 50 & $01 / 07 / 2016$ \\
\hline
\end{tabular}

\section{METHODOLOGY}

\subsection{SAR time-series data-based burn scar detection}

Several studies for SAR-based burn scar detection were undertaken in the European Mediterranean environment. Most studies focus on backscatter changes in pre- and postevent data sets resulting from physical modifications in the vegetation layer. Promising results are achieved using Cband SAR data for burnt area detection in Central Portugal $[5,6]$. The burnt areas are distinguishable regardless of rainfall, although the wet season showed higher backscatter values than the dry season. The utility of X-, C-, and L- band data for fire severity assessment in dry and wet environmental conditions are confirmed by [11]. Moreover, $[1,2]$ approved the detection capabilities of X-band SAR data for burn scar mapping and investigated differences in the backscatter signal dependent on pre-fire vegetation and weather conditions. L-band ALOS PALSAR data over Sardinia [10], and C-band data over pine canopies [8] have also been used for burnt area detection. Investigations of X-, $\mathrm{C}$ - and L-band repeat-pass interferometric SAR coherence are conducted by [11].

The collected S-1 Single Look Complex data available for the study area are pre-processed to SAR interferograms based on the method of [12]. Several statistics are computed based on the SAR amplitude and coherence information: the absolute amplitude difference, the absolute coherence difference, and the absolute deviation of the coherence to the time-series mean. Thereby, it is important to notice that the coherence pair including the time of the fire event is excluded from the computation of the mean. A semiautomated object-based classification of the burnt area based on the absolute deviation of the coherence to the mean is performed. This classification procedure consists of empirical thresholding and subsequent region growing of initially derived seed regions.

\subsection{Optical data-based burn scar detection}

BURNOUT is a fully-automatic burn scar mapping tool which was developed at SERTIT-ICube (Strasbourg, France) within ASAPTERRA. It is based on free Orfeo Toolbox and GDAL libraries and allows extracting firerelated crisis information within a few minutes.

The development focuses on free data available at a high spatial resolution from $10 \mathrm{~m}$ to $30 \mathrm{~m}$ with repeat cycles between 5 and 16 days. Consequently, BURNOUT uses USGS's Landsat-8 optical imagery and the ESA's S-2 data. The main concept (see workflow in Fig. 1) is to compare pre-event and post-event images in order to extract the burn scar based on three spectral indices: normalized burn ratio (NBR), burned area index (BAI) [4,9], and the Normalized Vegetation Index (NDVI). Further, it is capable to indicate the severity of a wildland fire. The fire severity corresponds to a classification of the NBR index over the burn scar into four classes (from very low severity to very high).

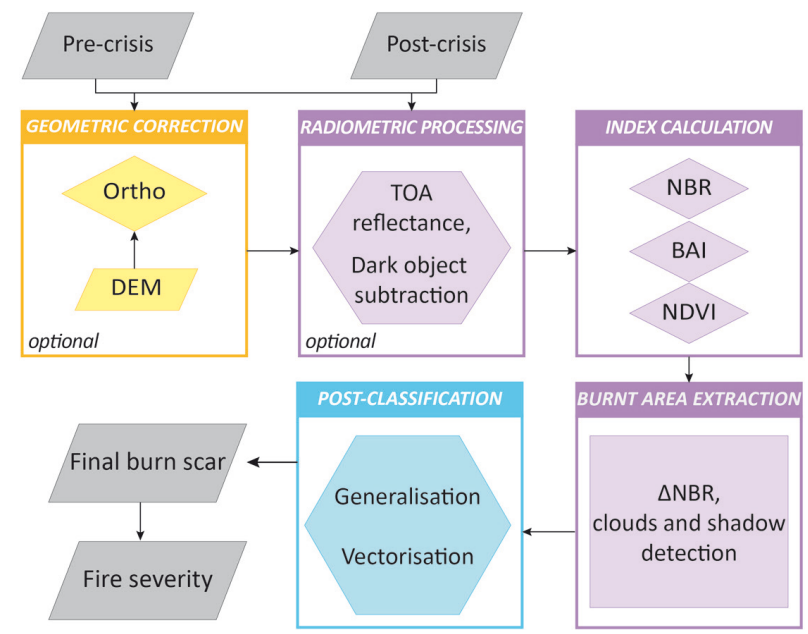

Fig. 1: BURNOUT workflow.

\subsection{Post-fire soil erosion susceptibility index}

Further, a spatial modelling approach is developed to derive a soil detachment/erosion indicator based on the Revised Universal Soil Loss Equation (RUSLE) model [7]. Both the standard and modified equations can be properly applied only to areas experiencing net erosion. Depositional areas should be excluded from the study area. The results can also be interpreted as an extreme case with maximum possible 
spatial extent of erosion. Hence, areas at risk can be estimated providing information on current erosion and its trends. Moreover, higher soil erosion risk can be linked to a number of factors such as steep slopes, climate characteristics, inappropriate land use, land cover patterns (e.g. sparse vegetation) and ecological disasters (e.g. forest fires). The RUSLE soil erosion model is illustrated in Fig. 2.

Parameters $R$ (rain erosivity) and $K$ (soil erodibility) are derived from the free JRC Eurosoil database, $C$ (landcover) is obtained from satellite data, and factor $L S$ (slopes, slope length) is computed from a digital surface model (DSM). Given the lack of information on prevention practices it has been decided to not consider the $\mathrm{P}$ factor. The resulting index is named the Soil erosion susceptibility index (SESI).

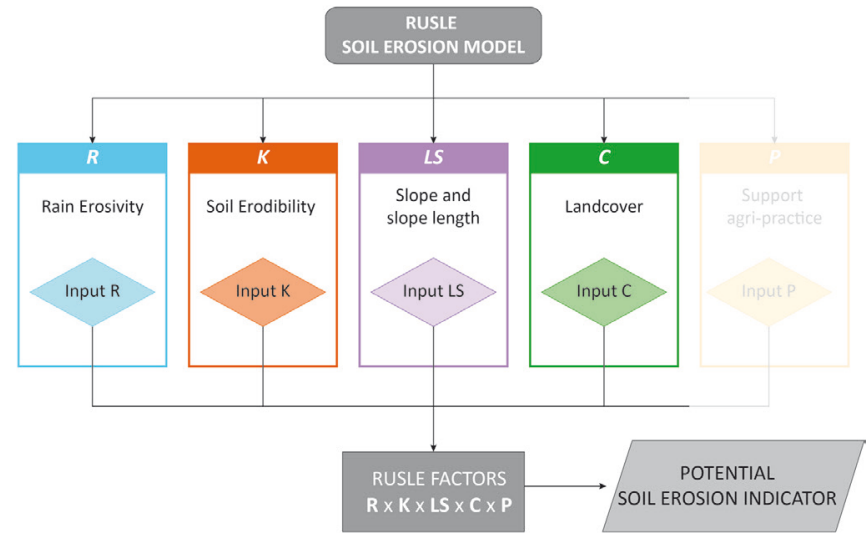

Fig. 2: The RUSLE soil erosion model.

\section{RESULTS}

\subsection{SAR data-based results}

In Fig. 3 several statistical parameters of the S-1 time series are visualized. The first row shows the absolute amplitude difference of consecutive S-1 data pairs. Surprisingly, it is not possible to identify the burnt area based on this parameter in this study area as there is no significant change in backscatter between the pre- and post-event data. In contrast to this, the coherence is better suited for the identification of the burnt area. Especially the absolute deviation of the coherence to the time-series mean shows a strong signature. The coherence is influenced by changes on the ground in the time between the two SAR acquisitions. High coherence represents stable conditions while low coherence values represent strong changes on the ground. A fire event changes the characteristics of the SAR backscatter at the ground and leads to a decrease of the coherence for the image pair that includes the time of the fire event. The advantage of the absolute deviation of the coherence to the mean compared to the single absolute coherence difference is that small changes not related to the fire event are averaged. Using this parameter in the semi-automated object-based approach described in chapter 3.1 large parts of the burn scar could be derived (see Fig. 3).

\subsection{Optical data-based results}

Fig. 4a shows the automatically derived burnt area extent obtained firstly by the use of the BURNOUT tool using the pre- and post-event S-2 data. The extent of the burnt area is refined by photo-interpretation on Pléiades data acquired on $13 / 08 / 2016$. The burnt area represents a surface of 2589 ha. Based on the burn scar the fire severity (Fig. 4b) is calculated which shows the intensity of the fire's impact.
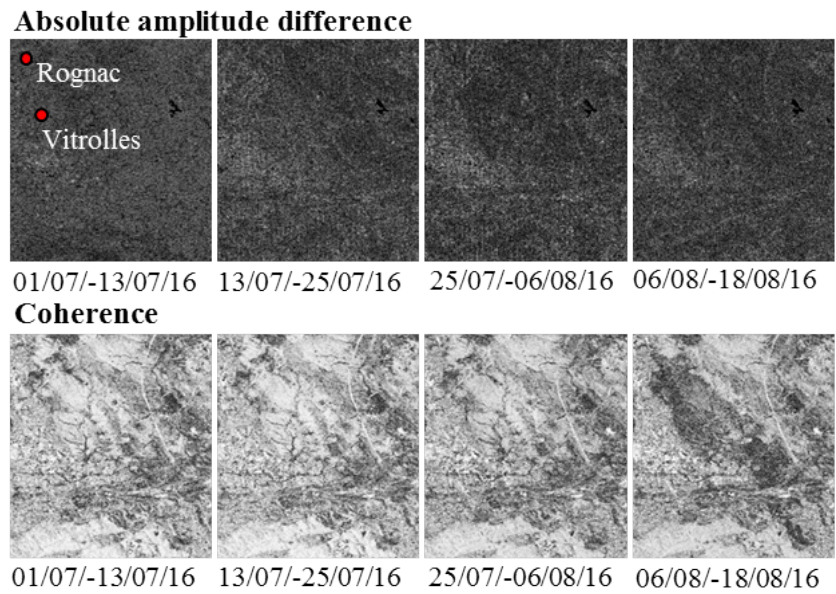

Absolute deviation of the coherence to the time series mean

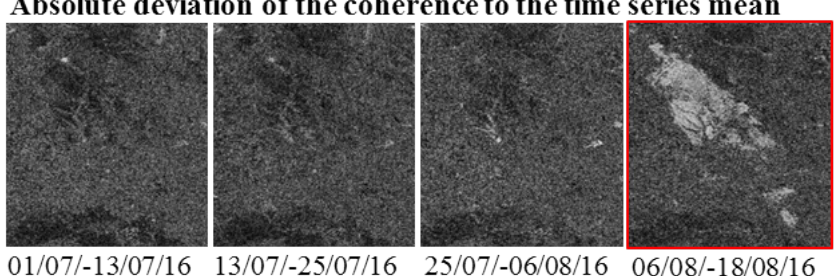

Absolute coherence difference

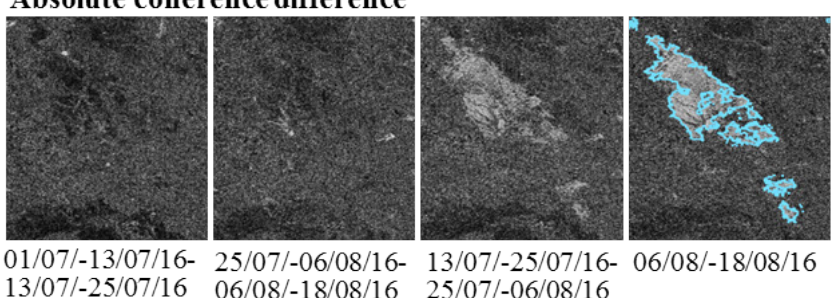

13/07/-25/07/16 06/08/-18/08/16 25/07/-06/08/16

Fig. 3: Statistical parameters of the S-1 time series and classification result based on S-1 coherence data.

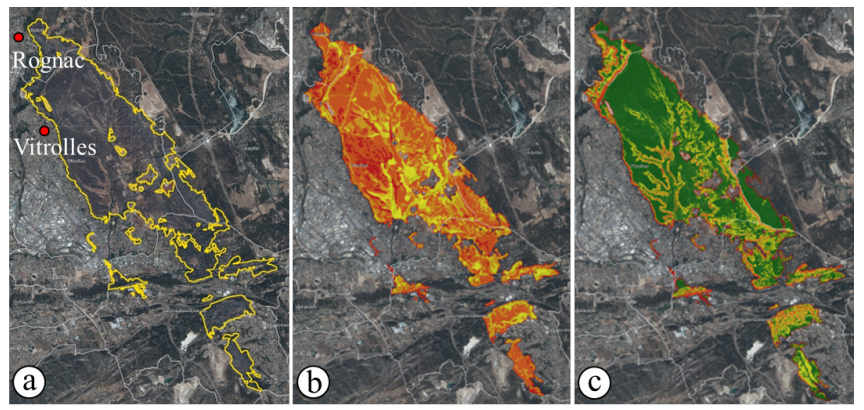

Fig. 4: a) Burn scar and b) fire severity (from very low (yellow) to very high severity (red) derived from S-2 and refined by Pléiades data; c) soil erosion susceptibility index (from low (green) to very high (red) erosion susceptibility). 
The NBR index is used to assess the fire severity. This step requires a SWIR band only available on S-2 data. The result is adapted and interpolated to the Pléiades-HR data. Four severity classes are defined: very low to low, low to moderate, moderate to high, high to very high. The highest severity classes are often located close to urban areas.

A DSM derived from Pléiades data of 13/08/2016 is used to calculate the soil erosion susceptibility (Fig. 4c) following the fires. Five classes of susceptibility are defined: low, low to moderate, moderate, high, very high. The most important risk is often in steep areas, especially close to the Rognac and Vitrolles urban areas.

\subsection{Comparison of SAR and optical data-based results}

The burn scars derived from SAR and optical data show an overlap of $61.7 \%$ (Fig. 5). Using the S-1 data $38.3 \%$ of the optical data-based extent could not be detected and $4.1 \%$ are overestimated. The overlap percentages demonstrate that the described S-1 based procedure enables a rough mapping of burnt areas. Even if optical data are the preferred source for burn-scar mapping, within rapid mapping activations S-1 coherence data are an alternative to derive the fire extent if no optical data are available due to cloud coverage or smoke of an active fire event.

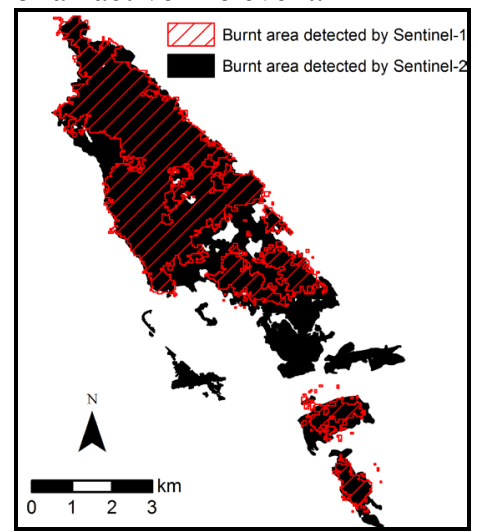

Fig. 5: Comparison between the burn scars derived from S-1 and S-2/Pléiades data.

\section{CONCLUSION AND OUTLOOK}

Within this study processing chains for the rapid mapping of fire burn scars, fire severity masks and soil susceptibility indices based on S-2 and Pléiades data were developed and applied to a fire event near Marseille, France, in August 2016. Further, the usefulness of coherence time-series data of the S-1 InSAR Browse Service of ESA's GEP for a rough mapping of burn scars was demonstrated. As only S-1A data with a temporal resolution of 12 days were available for this fire event it is assumed that the S-1A and S-1B constellation providing interferometric pairs at a 6 days repeat cycle will increase the S-1 based classification accuracy. This would decrease the temporal correlation caused by changes on the ground, which are not related to the fire event itself.

\section{REFERENCES}

[1] E. Bernhard, A. Twele, and M. Gähler, "Rapid Mapping of Forest Fires in the European Mediterranean Region - a Change Detection Approach Using X-Band SAR Data", Photogrammetrie, Fernerkundung, Geoinformation, 4, pp. 261-270, 2011.

[2] E. Bernhard, A. Twele, and S. Martinis, "The effect of vegetation type and density on X-band SAR backscatter after forest fires", Photogrammetrie, Fernerkundung, Geoinformation, 4, pp. 275-285, 2014.

[3] Chuvieco, E. "Global impacts of fire". In: Chuvieco, E. (Ed.): Earth observation of wildland fires in Mediterranean ecosystems, Springer, pp. 1-11, 2009.

[4] E. Chuvieco, M.P. Martin, and A. Palacios, "Assessment of different spectral indices in the red-near-infrared spectral domain for burnt land discrimination", International Journal of Remote Sensing, 23(23), pp. 5103-5110, 2002.

[5] Gimeno, M., San-Miguel Ayanz, M., and Liberta, G., "Fire scar detection in central Portugal using RADARSAT-1 and ERS-2 SAR data", IEEE International Geoscience and Remote Sensing Symposium, I-VII, pp. 2491-2493, 2003.

[6] Gimeno, M., and Ayanz, J., "Evaluation of Radarsat-1 data for identification of burnt areas in southern Europe", Remote Sensing of Environment, 104, pp. 346-359, 2004.

[7] I.Z. Gitas, K. Douros, C. Minakou, G.N. Silleos, and C.G. Karydas, "Multi-temporal soil erosion risk assessment in North Chalkidiki using a modified USLE raster model", EARSeL eProceedings, 8, 2009.

[8] V. Kalogirou, P. Ferrazzoli, A. Della Vecchia, and M. Foumelis, "On the SAR backscatter of burned forests: a modelbased study in C-Band, over burned pine canopies", IEEE Trans Geosc Remote Sens, 52, pp. 6205-6215, 2014.

[9] C.H. Key, and N.C. Benson, "Measuring and remote sensing of burn severity: the CBI and NBR". In L.F. Neuenschwander, K.C. Ryan (Eds.), Proceedings Joint Fire Science Conference and Workshop, Vol. II, Boise, 15-17 June 1999, 1999.

[10] N. Mari, G. Laneve, E. Cadau, and X. Porcasi, "Fire Damage Assessment in Sardinia: the use of ALOS/PALSAR data for post fire effects management", European Journal of Remote Sensing, 45, pp. 233-241, 2012.

[11] M. Tanase, M. Santoro, J. de la Riva, F. Pérez-Cabello, and T. Toan, "Sensitivity of X-, C-, and L-Band SAR Backscatter to Burn Severity in Mediterranean Pine Forests", IEEE Transactions on Geoscience and Remote Sensing, 48 (10), pp. 3663-3675, 2010.

[12] N. Yague-Martinez, P. Prats-Israola, F. Rodriguez Gonzalez, R. Brcic, R. Shau, D. Geudtner, M. Eineder, and R. Bamler, "Interferometric processing of Sentinel-1 TOPS data". IEEE Trans Geosc Remote Sens g, 54 (4), pp. 2220-2234, 2016. 